USEtox - The UNEP-SETAC toxicity model: recommended characterisation factors for human toxicity and freshwater ecotoxicity in Life Cycle Impact Assessment

Ralph K. Rosenbaum ${ }^{1 *}$, Till M. Bachmann ${ }^{2}$, Lois Swirsky Gold ${ }^{3}$, Mark A.J. Huijbregts ${ }^{4}$, Olivier Jolliet ${ }^{5}$, Ronnie Juraske ${ }^{6,7}$, Annette Koehler ${ }^{7}$, Henrik F. Larsen ${ }^{8}$, Matthew MacLeod ${ }^{9}$, Manuele Margni ${ }^{1}$, Thomas E. McKone ${ }^{10}$, Jérôme Payet ${ }^{11}$, Marta Schuhmacher ${ }^{6}$, Dik van de Meent ${ }^{4,12}$, Michael Z. Hauschild ${ }^{8}$

${ }^{1}$ CIRAIG, École Polytechnique de Montréal, Department of Chemical Engineering, Montréal (Québec) H3C 3A7, Canada

${ }^{2}$ European Institute For Energy Research, Emmy-Noether-Strasse 11, 76131, Karlsruhe, Germany

${ }^{3}$ University of California Berkeley, and Children's Hospital Oakland Research Institute (CHORI) Oakland, California, USA

${ }^{4}$ Department of Environmental Science, Radboud University Nijmegen, Nijmegen, The Netherlands

${ }^{5}$ Center for Risk Science and Communication, University of Michigan, Ann Arbor, Michigan, USA

${ }^{6}$ Chemical Engineering School, Rovira i Virgili University, Tarragona, Spain

${ }^{7}$ ETH Zurich, Institute of Environmental Engineering, Ecological Systems Design, Zurich, Switzerland

${ }^{8}$ DTU Management Engineering, Technical University of Denmark, Lyngby, Denmark

${ }^{9}$ ETH Zurich, Institute for Chemical and Bioengineering, Zurich, Switzerland

${ }^{10}$ University of California Berkeley, Lawrence Berkeley National Laboratory, Berkeley, California, USA

${ }^{11}$ Institute of Environmental Science and Technology, École Polytechnique Fédérale de Lausanne, Lausanne, Switzerland

${ }^{12}$ National Institute of Public Health and the Environment (RIVM), Bilthoven, Netherlands

February 3, 2008

This work was supported in part by Interagency Agreement DW-89-93058201-1 with Lawrence Berkeley National Laboratory through the US Department of Energy under Contract Grant No. DEAC02-05CH11231. 


\title{
USEtox - The UNEP-SETAC toxicity model: recommended characterisation factors for human toxicity and freshwater ecotoxicity in Life Cycle Impact Assessment
}

\author{
Ralph K. Rosenbaum ${ }^{1 *}$, Till M. Bachmann ${ }^{2}$, Lois Swirsky Gold ${ }^{3}$, Mark A.J. Huijbregts ${ }^{4}$, Olivier Jolliet ${ }^{5}$, Ronnie \\ Juraske $^{6,7}$, Annette Koehler ${ }^{7}$, Henrik F. Larsen ${ }^{8}$, Matthew MacLeod ${ }^{9}$, Manuele Margni ${ }^{1}$, Thomas E. McKone ${ }^{10}$, \\ Jérôme Payet $^{11}$, Marta Schuhmacher ${ }^{6}$, Dik van de Meent ${ }^{4,12}$, Michael Z. Hauschild ${ }^{8}$
}

${ }^{1}$ CIRAIG, École Polytechnique de Montréal, Department of Chemical Engineering, 2900 Édouard-Montpetit, P.O. Box 6079, Stn. Centre-ville, Montréal (Québec) H3C 3A7, Canada;

${ }^{2}$ European Institute For Energy Research (EIFER), Emmy-Noether-Strasse 11, 76131 Karlsruhe, Germany;

${ }^{3}$ University of California Berkeley, and Children's Hospital Oakland Research Institute (CHORI), Oakland, California, USA;

${ }^{4}$ Department of Environmental Science, Radboud University Nijmegen, P.O. Box 9010, 6500 GL Nijmegen, The Netherlands;

${ }^{5}$ Center for Risk Science and Communication, University of Michigan, Ann Arbor, Michigan, USA;

${ }^{6}$ Chemical Engineering School. Rovira i Virgili University, Tarragona, Spain;

${ }^{7}$ ETH Zurich, Institute of Environmental Engineering, Ecological Systems Design, Wolfgang-Pauli-Strasse 15, CH-8093 Zurich, Switzerland;

${ }^{8}$ DTU Management Engineering, Technical University of Denmark, Produktionstorvet, Building 424, DK-2800 Lyngby, Denmark;

${ }^{9}$ ETH Zurich, Institute for Chemical and Bioengineering, Wolfgang-Pauli-Strasse 10, CH-8093 Zurich, Switzerland;

${ }^{10}$ University of California Berkeley, Lawrence Berkeley National Laboratory, California, USA;

${ }^{11}$ Institute of Environmental Science and Technology, École Polytechnique Fédérale de Lausanne, Lausanne, Switzerland;

${ }^{12}$ National Institute of Public Health and the Environment (RIVM), Bilthoven, Netherlands;

* Corresponding author (ralph.rosenbaum@polymtl.ca; Tel: +1 514-340-4711 ext.: 3368; Fax: +1 514-340-5913)

\begin{abstract}
Background, Aim and Scope. In 2005 a comprehensive comparison of LCIA toxicity characterisation models was initiated by the UNEP-SETAC Life Cycle Initiative, directly involving the model developers of CalTOX, IMPACT 2002, USES-LCA, BETR, EDIP, WATSON, and EcoSense. In this paper we describe this model-comparison process and its results - in particular the scientific consensus model developed by the model developers. The main objectives of this effort were (i) to identify specific sources of differences between the models' results and structure, (ii) to detect the indispensable model components, and (iii) to build a scientific consensus model from them, representing recommended practice.

Methods. A chemical test set of 45 organics covering a wide range of property combinations was selected for this purpose. All models used this set. In three workshops, the model comparison participants identified key fate, exposure and effect issues via comparison of the final characterisation factors and selected intermediate outputs for fate, human exposure and toxic effects for the test set applied to all models.

Results. Through this process, we were able to reduce inter-model variation from an initial range of up to 13 orders of magnitude down to no more than 2 orders of magnitude for any substance. This led to the development of USEtox, a scientific consensus model that contains only the most influential model elements. These were, for example, process formulations accounting for intermittent rain, defining a closed or open system environment, or nesting an urban box in a continental box.
\end{abstract}

Discussion. The precision of the new characterisation factors (CFs) is within a factor of 100-1000 for human health and 10100 for freshwater ecotoxicity of all other models compared to 12 orders of magnitude variation between the CFs of each model respectively. The achieved reduction of inter-model variability by up to 11 orders of magnitude is a significant improvement.

Conclusions. USEtox provides a parsimonious and transparent tool for human health and ecosystem CF estimates. Based on a referenced database, it has now been used to calculate CFs for several thousand substances and forms the basis of the recommendations from UNEP-SETAC's Life Cycle Initiative regarding characterization of toxic impacts in Life Cycle Assessment.

Recommendations and Perspectives. We provide both recommended and interim (not recommended and to be used with caution) characterisation factors for human health and freshwater ecotoxicity impacts. After a process of consensus building among stakeholders on a broad scale as well as several improvements regarding a wider and easier applicability of the model, USEtox will become available to practitioners for the calculation of further CFs.

Keywords: Consensus model, life cycle impact assessment, LCIA, characterization modelling, comparison, harmonisation, human exposure, toxic impact, human toxicity, freshwater ecotoxicity, comparative impact assessment, characterization factors

\section{Background, Aim and Scope}

In 2002, the United Nations Environment Program (UNEP) and the Society for Environmental Toxicology and Chemistry (SETAC) launched an International Life Cycle Partnership, known as the Life Cycle Initiative, to enable users around the world to put life cycle thinking into effective practice. The Life Cycle Impact Assessment (LCIA) programme within this initiative aims to 1) establish recommended methodologies and guidelines for the different impact categories, and 
ultimately consistent sets of [characterisation] factors, and 2) make results and recommendations widely available for users through the creation of an information system that is accessible worldwide (see Jolliet et al. (2003a)). In this context, identification and quantification of impacts on human health and ecosystems due to emissions of toxic substances are of central importance in the development of sustainable products and technologies. Toxicity indicators for human health effects and ecosystem quality are necessary both for comparative risk assessment and for LCAs applied to chemicals and emission scenarios. Yet, in practice these toxicity factors are not typically addressed in LCIA for many reasons, one of which is that different methods often fail to arrive at the same toxicity characterisation score for a substance (Pant et al. 2004). The Task Force on ecotoxicity and human toxicity impacts, established under the LCIA programme, aimed at making recommendations for characterisation factors (CF) for toxicity, using a methodology simple enough to be used on a world-wide basis for a large number of substances but incorporating broad scientific consensus. To reach this goal a comprehensive comparison of existing human and ecotoxicity characterisation models was carried out to establish recommended practice in chemical characterization for LCIA by means of constructing a scientific consensus model.

Several methodologies have been published that account for fate, exposure and effects of substances and provide cardinal impact measures. Among these methods are IMPACT 2002 (Jolliet et al. 2003b, Pennington et al. 2005), USES-LCA (Huijbregts et al. 2000), Eco-Indicator 99 (Goedkoop et al. 1998) and CalTOX (Hertwich et al. 2001, McKone et al. 2001, McKone 2001). These methods adopt environmental multimedia, multipathway models to account for the environmental fate and exposure processes. Characterisation methods like EDIP (Hauschild \& Wenzel 1998) account for fate and exposure relying on key properties of the chemical.

Model comparisons on the level of chemical fate - without considering exposure - have been published by Cowan et al. (1994), Maddalena et al. (1995), Kawamoto et al. (2001), Wania and MacKay (2000), Bennett et al. (2001), Wania and Dugani (2003), Stroebe et al. (2004), and Scheringer et al. (2004). An OECD expert panel compared nine multimedia models by applying a set of 3175 hypothetical chemicals (Fenner et al. 2005). In this effort, the most influential model elements were identified and incorporated into a consensus model, called "The Tool" (Wegmann et al. 2008), which calculates long range transport potentials (LRTP) and overall persistence for chemical hazard assessment. Depending on chemical partitioning properties, the OECD study identified the following model elements as influential for the LRTP calculation: setup and parameterisation of regional, continental and global scales in a nested structure; transport in air, river water and seawater; full spatial coupling between media; geo-referenced surface area ratios, degradation of the aerosolbound fraction; setup of the environmental conditions; and zonal averaging of environmental parameters.

Some comparisons have also been conducted taking into account the (human) exposure and/or toxic effects part of impact models. Huijbregts et al. (2005a) compared inhalation and ingestion intake fractions (iF) calculated by CalTOX and USESLCA for 365 compounds. Several model characteristics were found to be important sources of differences, e.g. presence and treatment of a seawater compartment, layering of the soil compartment, consideration of rain events and drinking water treatment. A few studies have dealt with the comparison of characterisation factors in the context of LCIA, among them Dreyer et al. (2003) and Pant et al. (2004) who concluded that for toxic impacts on human health and ecosystems more detailed analyses are needed to identify causes for the large differences found between the methods. In the OMNIITOX project, a detailed model comparison was conducted with CalTOX, IMPACT 2002 and USES-LCA, and a systematic approach was developed to compare models and identify sources of differences between the models on the level of environmental mechanisms (Margni 2003, Rosenbaum 2006).

These studies were used as the starting point for the UNEP-SETAC model comparison. Although other studies have been published dealing with the comparison of multimedia fate models, few attempts have been made to compare models capable of estimating fate and exposure. Even less effort has been made to compare models on the level of toxic effects and final characterisation factors. Finding a scientific consensus among method developers and subsequently a broad consensus among all stakeholders results in a recommended method and sound user guidance, that will greatly enhance the practical implementation of toxicity impacts in LCA. This research aimed to address these issues by:

- Comparison of seven toxicity characterisation models applying a chemical test set comprising 45 organic substances to identify the most influential model choices.

- Development of a scientific consensus model - named USEtox in recognition of the UNEP-SETAC Life Cycle Initiative under which it was developed;

- Providing recommended LCIA characterization factors for more than 1000 chemicals for both human toxicity and aquatic freshwater ecotoxicity;

- Providing recommendation for future model development.

This paper begins with a description of the principles that guided the model development, the main features of USEtox and of the other models used for the comparison exercise, and the chemical database used to calculate characterization factors. It then summarizes the results from the UNEP-SETAC model comparison study regarding recommended characterisation factors and the development of a scientific consensus model, called USEtox, for chemical impact characterisation related to human toxicity and freshwater ecotoxicity. This paper is part of a series of publications presenting the process of scientific consensus building (Hauschild et al. 2008) as well as the comparison results and the USEtox model in detail regarding 1) chemical fate and ecotoxicity, 2) human exposure, and 3) human health effects respectively (the latter three papers are currently being prepared). 


\section{Methods}

\subsection{Principles and process for USEtox development}

Expert workshops: The model development had as a foundation the recommendations of a series of expert workshops (Jolliet et al. 2006, Ligthart et al. 2004, McKone et al. 2006). Their recommendations were used to construct a model that represented the consensus of experts about what a meaningful toxic impact characterisation model for human toxicity and freshwater ecotoxicity needed to take into account in the context of comparative assessment.

Model comparison: A quantitative comparison was conducted on seven existing LCIA models to identify the most influential parameters and reasons for differences between models. The models included in the comparison were selected in an open process in which developers of models characterizing environmental fate, human exposure, human toxicity, and ecotoxicity were invited to participate. This invitation was accepted by the developers of CalTOX (McKone et al. 2001), USA; IMPACT 2002 (Pennington et al. 2005), Switzerland; USES-LCA (Huijbregts et al. 2005c), Netherlands; BETR (MacLeod et al. 2001), Canada and USA; EDIP (Wenzel et al. 1998), Denmark; WATSON (Bachmann 2006), Germany; and EcoSense (EC 1999, 2005), Germany. Not all models included in the comparison were capable of describing the entire emission-to-characterisation factor relationship, but all models were compared for midpoints that they could calculate. A succinct qualitative comparison of the models can be found in the Supporting Information.

This comparison was carried out using a chemical test set composed of 45 organic substances (Margni 2003, Margni et al. 2002), covering a wide range of property combinations according to the following criteria: environmental partitioning, exposure pathways, overall persistence, long range transport in air, the importance of feedback between environmental media according to Margni et al. (2004), and extreme hydrophobicity. The test set of non-dissociating and non-amphiphilic organic chemicals is provided in the Supporting Information. For the substances in the chemical test set, each model developer calculated with his own model, results representing fate, exposure, effects and overall impact characterisation factors. In a series of workshops (Bilthoven 5/2006, Paris 8/2006, and Montreal 11/2006), the results were discussed in order to identify the main reasons for differences. Between the workshops a list of specific changes was implemented in each model with the goal of harmonising the models, removing unintended differences.

Development principles: Finally, USEtox was developed following a set of principles including:

1. Parsimony - as simple as possible, as complex as necessary.

2. Mimetic - not differing more from the original models than these differ among themselves;

3. Evaluated - providing a repository of knowledge through evaluation against a broad set of existing models;

4. Transparent - being well documented, including the reasoning for model choices.

The scientific consensus model USEtox (named in recognition of the UNEP-SETAC Life Cycle Initiative under which it was developed) is the main outcome of the comparison exercise, and its name also conveys the message that the toxicity categories should be included in LCA.

\subsection{USEtox short description}

USEtox calculates characterisation factors for human toxicity and freshwater ecotoxicity. As demonstrated in Fig. 1, assessing the toxicological effects of a chemical emitted into the environment implies a cause-effect-chain that links emissions to impacts through three steps: environmental fate, exposure, and effects.

\section{Fig. 1}

Linking these, a systematic framework for toxic impacts modelling based on matrix algebra was developed within the OMNIITOX project (Rosenbaum et al. 2007) and peer-reviewed in a UNEP-SETAC workshop by an independent expert panel, who recommended the framework for further developments within the Life Cycle Initiative, where it was then adopted for USEtox (Jolliet et al. 2006). The links of the cause-effect chain are modelled using matrices populated with the corresponding factors for the successive steps of fate $(\overline{F F})$ in [day], exposure $(\overline{X F})$ in [day ${ }^{-1}$ ] (only human toxicity), and effects $(\overline{E F})$ in $\left[\right.$ cases $/ \mathrm{kg}_{\text {intake }}$ ] for human toxicity or $\left[\mathrm{PAF} \cdot \mathrm{m}^{3} / \mathrm{kg}\right.$ ] for ecotoxicity. This results in a set of scale-specific characterisation factors $(\overline{C F})$ in [cases $\left./ \mathrm{kg}_{\text {emitted }}\right]$, as shown in Equation (1).

$$
\overline{C F}=\overline{E F} \cdot \overline{X F} \cdot \overline{F F}=\overline{E F} \cdot \overline{i F}
$$

As depicted in Fig. 2 USEtox spans two spatial scales. The continental scale consists of six environmental compartments: urban air, rural air, agricultural soil, industrial soil, freshwater and coastal marine water. The global scale has the same structure as the continental scale but without the urban air, and accounts for impacts outside the continental scale. The main compartmental characteristics are listed in Table 1. The landscape parameters used can be found in the supporting information. The fate model calculates the mass increase [kg] in a given medium due to an emission flow [kg/day]. The unit of the fate factor is in days. It is equivalent to the time-integrated concentration $\mathrm{x}$ volume over the infinite of a pulse emission (Heijungs et al. 1992, Mackay \& Seth 1999). Inter-media transport and removal processes at the two spatial scales required to calculate the fate factor matrix $\overline{F F}$ will be further explained in the respective chemical-fate paper currently in preparation. The emission scenarios are continental emission to urban air, rural air, freshwater and agricultural soil. The human exposure model quantifies the increase in amount of a compound transferred into the human population based on the concentration increase in the different media. The human exposure factors in the exposure matrix $\overline{X F}$ at the two geographical scales include exposure through inhalation of (rural and urban) air, and ingestion of drinking water (untreated surface freshwater), leaf crops (exposed produce), root crops (unexposed produce), meat, milk, and fish from freshwater and marine aquatic compartments, for the total human population. Human exposure factors have the dimension day ${ }^{-1}$. The 
exposure parameters used are listed in the supporting information. The fate and the exposure matrices combine into the intake fraction matrix $(\overline{i F})$ that describes the fraction of the emission that is taken in by the overall exposed population. Further details will be discussed in the respective exposure paper currently in preparation. The ecological exposure factor equals the dissolved fraction of a chemical (dimensionless) and accounts for the bioavailability of a chemical by converting the fate factors in terms of total concentration to dissolved concentration.

\section{Fig. 2}

Human effect factors in USEtox relate the quantity taken in by the population via ingestion and inhalation to the probability of adverse effects (or potential risk) of the chemical in humans. It is based on toxicity data for cancer and non-cancer effects derived from laboratory studies. Under the assumption of a linear dose-response function for each disease endpoint and intake route, the human effect factor is calculated as $0.5 / \mathrm{ED}_{50}$, where the $\mathrm{ED}_{50}$ is the life-time daily dose resulting in a probability of effect of 0.5 . We allow for up to four separate human effect factors: cancer from ingestion exposure, noncancer effects from ingestion exposure, cancer from inhalation exposure, and non-cancer effects from inhalation exposure. Human effect factors have the dimension disease cases/kg intake. Differences in metabolic activation of chemicals between animal tested and humans are not considered. For further insights into the human health effects step, we refer to the related paper currently in preparation. For freshwater ecosystems, the effect factor is calculated using the same linear assumption used for the human effect factor i.e. linearity in concentration-response which results in a slope of $0.5 / \mathrm{HC}_{50}$. $\mathrm{The}_{\mathrm{HC}}$, based on species-specific $\mathrm{EC}_{50}$-data, is defined as the hazardous concentration at which $50 \%$ of the species are exposed above their $\mathrm{EC}_{50}$. The $\mathrm{EC}_{50}$ is the effective concentration at which $50 \%$ of a population displays an effect (e.g. mortality). Aquatic ecotoxicological effect factors have the dimension $\mathrm{m}^{3} \cdot \mathrm{kg}^{-1}$.

After multiplication of the scale-specific fate factors, exposure factors, and effect factors (see equation 1), the final characterisation factor for human toxicity and aquatic ecotoxicity is calculated by summation of the characterisation factors from the continental and the global scale assessments. For human toxicity, carcinogenic and non-carcinogenic effects are also summed (assuming weighting factor equals 1), resulting in a single characterisation factor per emission compartment. The characterisation factor for human toxicity (Human Toxicity Potential) is expressed in Comparative Toxic Units $\left(\mathrm{CTU}_{\mathrm{h}}\right)$, providing the estimated increase in morbidity in the total human population per unit mass of a chemical emitted (cases. $\mathrm{kg}^{-1}$ ), assuming equal weighting between cancer and non-cancer due to a lack of more precise insights into this issue. The characterisation factor for aquatic ecotoxicity (Ecotoxicity Potential) is expressed in Comparative Toxic Units $\left(\mathrm{CTU}_{\mathrm{e}}\right)$ and provides an estimate of the potentially affected fraction of species (PAF) integrated over time and volume per unit mass of a chemical emitted (PAF $\mathrm{m}^{3} \cdot$ day $\cdot \mathrm{kg}^{-1}$ ).

These general principles resulted in the key elements displayed in Table 1, which summarizes the key requirements for running the consensus model and indicates how these have been addressed. It provides an overview of both expert recommendations that were used as a basis to build the model and model choices that have been particularly influential. The right column lists how these recommendations have been implemented in USEtox while maintaining transparency and parsimony.

\section{Table 1}

\subsection{Chemical database}

A database of chemical properties was set up with data aiming to a) have a consistent set of data b) of a certain minimum quality c) for as many chemicals as possible for which characterisation factors can be computed. This includes three types of datasets, 1) physico-chemical properties, 2) toxicological effect data on laboratory animals as a surrogate to humans and 3) ecotoxicological effect data for freshwater organisms. A complete list of the minimum dataset needed to run the model can be found in the supporting information. Recognizing that the primary objective of this task is not to generate and/or estimate chemical properties and toxicity data, we focused our effort on identifying and collecting existing reviewed databases for which scientific judgement was already made in selecting and recommending values from a large range of values collected from the literature. For each of the three types of datasets we 1) identified the existing databases, 2) defined a selection scheme and criteria for data gathering and 3) compiled the database for all the chemicals for which effect data are available.

Human effect data: Building on the workshop recommendations for comparative assessment of McKone et al. (2006), the effect factor takes as a point of departure the Effect Dose $50 \%\left(E_{50}\right)$ from the Carcinogenic Potency Database (CPDB) by Gold et al. (2008, 2005). For cancer, the harmonic mean of all positive $\mathrm{ED}_{50}$ is retained for the most sensitive species of animal cancer tests between mice and rats, after application of an allometric factor proportional to bodyweight to the power of 0.25 (Vermeire et al. 2001). The use of a harmonic mean rather than an arithmetic or geometric mean is consistent with the use of the inverse of the ED50 in the model. Furthermore, the harmonic mean is similar to the most potent site and has the advantage of using results from all positive experiments (Gold et al. 1989). Compared to previous data used in LCA, chemicals with all negative carcinogenic effect data were also included as true zero carcinogenic effect factors and distinguished from missing data. In the case of effects other than cancer, for most of the substances insufficient data were available to recalculate an ED50 with dose-response models. For chemicals with no evidence of carcinogenicity, the $\mathrm{ED}_{50}$ has been estimated from no-observed effect level (NOEL) by a NOEL-to-ED ${ }_{50}$ conversion factor. NOELs were derived from the IRIS database and from the World Health Organization. If relevant, conversion factors to extrapolate from short term to long term exposure were applied as well (see Huijbregts et al. (2005b) for further details). For both carcinogenic 
and non-carcinogenic effects, a route-to-route extrapolation has been carried out, assuming equal $\mathrm{ED}_{50}$ between inhalation and ingestion route and flagging the factor as interim when large differences may occur (see section 2.4).

Ecotoxicological effect data: Two databases with ecotoxicity effect data on average $\mathrm{EC}_{50}$ values (i.e. $\mathrm{HC}_{50} \mathrm{~s}$ ) were available, covering respectively 3498 (Van Zelm et al. 2007) and 1408 chemicals (Payet 2004); the first one being based on $\mathrm{EC}_{50}$ values from the RIVM e-toxBase (www.e-toxbase.com) and the second one on data mainly from ECOTOX (2001) and IUCLID (2000). Even though there is no consensus on which averaging principles $\mathrm{HC}_{50}$ should be estimated (on basis of trophic levels or single species) we pragmatically suggest to use these available $\mathrm{HC}_{50}$ data all based on geometric means of single species tests data (Larsen \& Hauschild 2007). Further, we prioritise chronic values as long as they represent measured $\mathrm{EC}_{50}$ values and are not extrapolated from NOEC values (Jolliet et al. 2006, Larsen \& Hauschild 2007). Second priority is given to well documented acute data, applying a best estimate extrapolation factor as an acute-to chronic ratio (ACR), e.g. 1.9 for organic substances, and 2.2 for pesticides - except for carbamate and organotin where no ACR were available from Payet (2004). The $\mathrm{HC}_{50}$ value, which is applied as effect factor, is then pragmatically based on averages of single species test data.

Physical-chemical data: the EPI Suite ${ }^{\mathrm{TM}}$ chemical database (USEPA 2007) has been selected as the default database. Freely available from the EPA website, it covers all the physical-chemical parameters included in the other databases (Howard, 2006, personal communication): PHYSPROP (Howard \& Meylan 1997), SOLV-DB (NCMS 2008), Handbook of Environmental Degradation Rates (Howard et al. 1991), and Environmental Fate Data Base (SRC 2008). Additional specific compilations for bioconcentration factors for fish (Meylan et al. 1999), biotransfer factors for milk and meat (Rosenbaum 2006), and degradation half-lives (Mackay et al. 2006, Sinkkonen \& Paasivirta 2000) were identified. As a general rule, whenever available, experimental data were favoured over estimated data. For selected chemical properties we adopted the following priority list for data selection:

- Bioconcentration factors for fish:

o Select among the 600+ measured data from the Meylan et al. (1999) compilation

o EPISuite data based referring to the bilinear model of Meylan et al. (1999), including correction factors

o Bilinear model of Meylan et al. (1999) without correction factors

- Biotransfer factors for milk and meat:

o Experimental data collected by Rosenbaum (2006), 75 entries for $\mathrm{BTF}_{\text {milk }}$ and 40 for $\mathrm{BTF}_{\text {meat }}$

o Estimation based on a modified version of the Travis \& Arms model, according to the TGD (EC 2003)

- Half-lives:

o Data from Sinkkonen \& Paasivirta (2000) for Dioxins and PCBs

o Mackay Handbook (Mackay et al. 2006)

o EPI Suite ${ }^{\mathrm{TM}}$, using factors from (Aronson et al. 2006) to convert the degradation probability in half-lives and multiplication factors of 1:4:9 to extrapolate degradation half-lives for water, soil and sediment compartments respectively (Phil Howard, personal communication).

\subsection{Distinction between recommended and interim characterisation factors}

In USEtox, a distinction was made between interim and recommended characterization factors, reflecting the level of reliability of the calculations in a qualitative way. First, characterisation factors for 'metals', 'dissociating substances' and 'amphiphilics' (e.g. detergents) were all classified as interim due to the relatively high uncertainty of addressing fate and human exposure for all chemicals within these substance groups. Dissociative substances were identified using a systematic procedure, based on $\mathrm{pKa}^{1}$, while amphiphilics have been classified by using a list of marketed detergents received from Procter \& Gamble (Rana Pant, 2008, personal communication). This preliminary flagging of chemicals with interim characterisation factors has been carried out at our best available knowledge. However, we stress the fact that it is always the responsibility of the user to verify if a given chemical is inorganic, dissociating or amphiphilic/surfactant and whether its CF has to be considered as interim. A report back to the authors will be greatly appreciated in such a case.

For the remaining set of chemicals, consensus has been reached that recommended aquatic ecotoxicological characterisation factors must be based on effect data of at least three different species covering at least three different trophic levels (or taxa) in order to ensure a minimum variability of biological responses.

For human health effects, recommended characterisation factors were based on chronic or subchronic effect data, while characterisation factors based on sub-acute data were classified as interim. Furthermore, if route-to-route extrapolation was applied to obtain ingestion or inhalation human health effect factors, a subdivision was made between recommended and interim characterisation factors. Human health characterisation factors based on route-to-route extrapolation from animal data were considered interim, if the primary target site is specifically related to the route of entry. In addition,

\footnotetext{
${ }^{1}$ The following procedure has been applied: (i) selected those (665) chemicals from the list of 5019 substances that had a pKa value listed (ii) scored substances that can donate a proton "a" and those that can accept a proton as "b" (iii) calculated the fraction of the substance that is expected to be present in its original, neutral form at $\mathrm{pH} 7$ (iv) flagged acids with $\mathrm{pKa}<6$ and bases with $\mathrm{pKa}>8$ " $\mathrm{F}$ " (note that these are the substances with $\mathrm{F}($ neutral) $<10 \%$ ). Chemicals that are listed as salts need special attention. If the Kow listed for these chemicals pertain to the salt form, the Kow may be used to estimate $\mathrm{Kp}$. If it pertains to the conjugated acid or base, it needs to be corrected: Neglecting the possible contribution of the ionic form to hydrophobicity, we can use the product $\mathrm{F}$ (neutral)*Kow as a basis for estimating Kaw, Kp and BCF.
} 
characterisation factors based on extrapolation from the ingestion to inhalation route of entry were also considered interim if the expected fraction absorbed via inhalation was a factor of 1000 higher compared to the fraction absorbed via ingestion. This factor of 1000 indicates that exposure by inhalation may be far more toxic than by ingestion for a few chemicals. In these cases, the interim characterization factor would underestimate the potential impact by inhalation.

We determined 789 recommended characterization factors for potential carcinogenic human health effects, and 344 for non-carcinogenic human health effects. Interim characterisation factors were determined for 217 carcinogenic chemicals and 71 non-carcinogenic chemicals. 417 of the carcinogenic characterization factors corresponded to chemicals with negative effect data, i.e. with a characterization factor close to $1 \mathrm{E}-50$ (to differentiate from non-available factors set to 0 ). This results in a number of recommended CFs for total human health effects of 991 (all CFs used must be classified as recommended) plus 260 interim CFs (at least one CF was classified as interim). For aquatic ecotoxicity, the substance coverage for recommended factors is 1299 chemicals. The 1247 substances with less than three species tested are included as interim factors. A full list of recommended and interim characterisation factors for both human health and freshwater ecotoxicity impacts for emissions to urban air, rural air, freshwater and agricultural soil are available in the supporting information, in Excel format. They are accompanied by a selection of relevant intermediary parameters such as central fate factors, intake fractions for inhalation and ingestion, effect factors for human health cancer and non-cancer as well as freshwater ecotoxicity. Interim CFs might be used in LCA studies but with great caution and under awareness of their large inherent uncertainty. In the case that an LCA result is dominated by impact scores based on interim CFs, we advise to proceed with great caution to their interpretation underlining that these factors are neither recommended nor endorsed. If improved data become available or the model is updated in the future, interim factors could eventually be recalculated and become recommended factors if consequently they fulfil the criteria. Such a process is foreseen for the maintenance of both model and database.

\section{Results}

\subsection{Model comparison results}

Fig. 3 and Fig. 5 show the results of the harmonisation. By showing the comparison graph for the last comparison round (Montreal workshop in November 2006) in combination with Fig. 4 and 6 we demonstrate the evolution of harmonisation of the models during the process. In the figures USEtox is used as reference model, and the plots thus demonstrate that the characterisation factors produced with USEtox fall within the ranges of the factors produced by the other characterisation models in the comparison. This is in accordance with the second development principle mentioned earlier, that it shall be mimetic, not differing more from the original models than these differ among themselves.

\subsubsection{Human health impacts}

Fig. 3 compares human health characterisation factors calculated by several models for continental emissions to rural air as a representative example; all other emission scenarios can be found in supporting information. The harmonisation of most influential model elements reduced variability to 4 orders of magnitude.

\section{Fig. 3}

For any substance in the plots, the range given by the results of the old characterization methods can be taken as measure of the model uncertainty accompanying the characterization factor produced by USEtox or by any of the other models. In order to quantify the precision of USEtox against the other models we employ the residual error (RE), also known as the standard error of the log of the estimate or the standard deviation of the log of residuals. The $R E$ and its use in such context is discussed by McKone (1993). The RE was calculated for both situations presented above, i.e. the USEtox CFs vs. the CFs of all other models before and after their harmonisation. The results are shown in Fig. 4 in terms of $R E$. The $R E$ is related to the squared geometric standard deviation: $G S D^{2}=10^{R E^{\wedge} 2}$, which represents the geometric factor that captures the two standard deviations prediction interval, i.e. the $95 \%$ confidence interval (mean value divided, respectively multiplied by the $G S D^{2}$ ).

Via harmonisation the $R E$ was reduced by a factor of two to three, which represents a narrowing of the variation among models within the $95 \%$ confidence interval by three to more than four orders of magnitude, now spanning four to six orders of magnitude instead of 10 to 14 orders of magnitude.

Fig. 4

\subsubsection{Freshwater ecosystem impacts}

Fig. 5 shows the model comparison of freshwater ecotoxicity characterisation factors after continental emissions to freshwater (all other emission scenarios are shown in supporting information). The adapted models showed a variation of three orders of magnitude with USEtox.

Fig. 5

As shown in Fig. 6 the harmonisation of the models reduced the $R E$ of the aquatic ecotoxicity characterisation factors by a factor of two to three, narrowing down the variation among models within the $95 \%$ confidence interval to only two to four orders of magnitude instead of six to ten orders of magnitude, which represents a reduction of variation/model uncertainty by two to three orders of magnitude.

Fig. 6 


\section{Discussion \\ 4.1 Scientific consensus model}

Initial differences among models for toxicity characterisation factors were considerably reduced by harmonisation, as their sources were identified. The results from the USEtox model fall within the range of those of the other models, emulating their results with a minimum of complexity. Applying USEtox to a well-referenced database, recommended characterisation factors are now available for:

- Human toxicity: 991 organic substances $(+260$ interim CFs);

- Freshwater ecotoxicity: 1299 organic substances (+1247 interim CFs).

As main findings of the workshops (further discussed in the papers currently under preparation), some of the model choices that were found to be particularly influential are:

- Set-up of the soil compartment, e.g. inclusion of sub-compartments, distinction between soil usage types, ...;

- Process formulations, e.g. sedimentation, intermittent rain, ...;

- Defining a closed or open system environment (i.e. open system: inclusion of a global spatial scale that accounts for impacts outside the continental scale which would be incorrectly attributed to the continental scale if the system was closed);

- For human toxicity:

o Nesting an urban box in a continental box (allowing to account for higher inhalation impacts in areas with higher population density);

o Calculating biotransfer and bioconcentration factors in food products;

o Harmonic means of $\mathrm{TD}_{50} \mathrm{~S}$ and $\mathrm{ED}_{50} \mathrm{~s}$ were taken as a starting point, using animal-human extrapolation factors of 4.1 for rats and 7.3 for mice, based on allometric factors.

- For ecotoxicity

o Disregarding impacts in the ocean which is modelled as a sink. The current version is only modelling impacts in the freshwater compartment.

0 Applying $\mathrm{HC}_{50}$ based on $\mathrm{EC}_{50}$ values as effect indicator representing the average sensitivity of the species for comparative purposes, rather than focusing on the most sensitive species as is frequently done in risk assessment.

\subsection{Uncertainty and Precision}

Based on comparisons among the different models, we estimate that the precision of the new CFs is within a factor of 1001000 for human health and 10-100 for freshwater ecotoxicity. Such a precision of 2 to 3 orders of magnitude is significantly lower than the roughly 12 orders of magnitude variation between the CFs of the different chemicals that we obtain from each individual model. The uncertainty range in model results is due to variation between the models and does not include parameter uncertainties attached to the input data used to calculate the CFs as input data was kept the same. As a first estimate of the underlying model uncertainty (i.e. without parameter uncertainty) inherent in the recommended CFs, Table 2 provides their $G S D^{2}$ under the assumption that they are log-normally distributed. These estimates are based on the residual error discussed in section 3.1.1.

\section{Table 2}

Apart from differences in model structure, important sources of uncertainty of the USEtox results are among others the uncertainty and variability related to input parameters and the lack of accurate mechanistic QSARs to estimate substance properties like carry-over rates to meat and milk, limited data on bioconcentration factors for fish, lacking data on chemical degradation rates and large uncertainties related to both human health and ecotoxic effect data. The latter comprise issues such as the use of chronic and acute data, route-to-route extrapolations (i.e. from oral administration in rodent tests to inhalation by humans) and the application of a linear dose-response curve for both the human health and the aquatic ecotoxicity effect factors calculation. Furthermore, we chose to set the human effect factor to zero if no toxicology information is available. The assumption of homogenous compartments, even for such complex media as soil or water, represents a further uncertainty as in the USEtox model any chemical entering these compartments is immediately diluted perfectly within the volume. The vegetation model used in the exposure model does not include any degradation process because data are not available. This will overestimate exposures of humans via agricultural produce and meat/milk, further increasing the uncertainty of biotransfer processes modelling in USEtox.

Both "recommended" and "interim" characterisation factors are provided. The main difference between recommended and interim characterisation factors is related either to the applicability of USEtox to the respective substances or the availability and quality of the necessary input data. Currently, USEtox is applicable to generic, non-dissociating and nonamphiphilic organic substances. Notably, it does not account for speciation and other important specific processes for metals, metal compounds, and certain types of organic chemicals. As the needed improvements in the modelling practice for these groups of compounds are still under elaboration, we decided to provide interim factors for the time being. Furthermore, for a number of chemicals, the minimum data quality could not be met, e.g. for estimation of the aquatic ecotoxicity effect factor in situations where data for less than three species were available. This led to the decision to not actually recommend factors for such substances while research is currently ongoing, but to at least provide interim characterisation factors that might be used if needed, but which are not endorsed by the UNEP-SETAC Initiative. The uncertainty of these factors is very large, but given the overall range of chemical variation they might be used with caution. 
As already mentioned, missing data and knowledge impose limitations to the use and interpretation of the model and its results. We also note that certain human exposure routes, such as indoor air and dermal exposure are currently not included. Limiting factors in terms of data availability are notably data on human toxicity, ecotoxicity, biotransfer, and degradation. For these important inputs we had to rely on QSAR methods with all their intrinsic uncertainties. For other endpoints such as marine or terrestrial ecosystems almost no experimental data are currently available. Further research should be undertaken to improve the respective data basis and bridge this data gap.

\section{Conclusions}

USEtox provides a parsimonious and transparent tool for human health and ecosystem CF estimates. It has been carefully constructed as well as evaluated via comparison with other models and falls within the range of their results while being less complex. It may thus serve as an interface between the more sophisticated state-of-the-art expert models (such as those compared in this study and which frequently change due to latest scientific developments being included) and the need of practitioners for transparency, broad stakeholder acceptance and stability of factors and methods applied in LCA. Based on a referenced database, USEtox has been used to calculate CFs for several thousand substances and forms the basis of the recommendations from UNEP-SETAC's Life Cycle Initiative regarding characterization of toxic impacts in Life Cycle Assessment. USEtox therefore provides the largest substance coverage presently available in term of numbers of chemicals covered. Furthermore, model uncertainty has partly been quantified. USEtox thus represents a significantly improved basis for a wider application of human health and ecotoxicity characterisation factors in LCA which will be further discussed via recommendations in the following section.

\section{Recommendations and Perspectives \\ 6.1 Guidance for the use of toxicity factors}

In LCA a toxicity impact score $\mathrm{IS}_{\mathrm{t}}$ is calculated as $\mathrm{IS}_{\mathrm{t}}=\sum_{\mathrm{i}}\left(\mathrm{CF}_{\mathrm{ti}} * \mathrm{M}_{\mathrm{i}}\right)$ with $\mathrm{M}_{\mathrm{i}}$ being the mass emitted per emission scenario i multiplied with the corresponding toxicity characterisation factor $\mathrm{CF}_{\mathrm{ti}}$ summed over all emission scenarios i. For example, benzo[a]pyrene emissions of $0.1 \mathrm{~kg}$ to continental air and $0.2 \mathrm{~kg}$ to continental freshwater (per functional unit respectively) would be characterised with a human toxicity impact score as follows: $\mathrm{IS}_{\mathrm{t}}=\mathrm{CF}_{\text {hum-tox-benzo[a]pyrene-to-cont-air }} * 0.1 \mathrm{~kg}+\mathrm{CF}_{\text {hum-tox- }}$ benzo[a]pyrene-to-cont-freshwater $* 0.2 \mathrm{~kg}=3.01 \mathrm{E}-6 \mathrm{CTU}_{\mathrm{h}} * 0.1 \mathrm{~kg}+1.26 \mathrm{E}-5 \mathrm{CTU} \mathrm{U}_{\mathrm{h}} * 0.2 \mathrm{~kg}=2.82 \mathrm{E}-6 \mathrm{CTU} / \mathrm{kg}$. This human toxicity impact score can then be summed with that of other substances from the inventory. The toxicity factors, i.e. characterisation factors, presented here must be used in a way that reflects the large variation of 10 orders of magnitude between chemical characterization factors as well as the 3 orders of magnitude uncertainty on the individual factors. This means that contributions of $1 \%, 5 \%$ or $90 \%$ to the total human toxicity score are essentially equal, but significantly larger than those of a chemical contributing to less than 1 per thousand or less than 1 per million of the total score. Disregarding this fact has been a major cause of complaints about the variability of these factors across impact assessment methods, whereas the most important chemicals were often the same within a factor 1000 across methods.

In practice, this means that for LCA practitioners, these toxicity factors are very useful to identify the 10 or 20 most important toxics pertinent for their applications. The Life Cycle Toxicity scores thus enable the identification of all chemicals contributing more than e.g. one thousandth to the total score. In most applications, this will allow the practitioner to identify 10 to 30 chemicals to look at in priority and perhaps more importantly, to disregard 400 other substances whose impacts are not significant for the considered application.

Once these most important substances have been identified, further analysis can be carried out on the Life Cycle Phase, application components responsible for these emissions, and the respective importance of fate, exposure and effect in determining the impacts of this chemical. Due to its simple and transparent matrix format, USEtox will also allow identification of the main exposure pathways, (e.g. inhalation, water ingestion, various food ingestion) as well as the relative importance of potential carcinogenic and non-carcinogenic effects in the overall score. The inclusion of an urban area as a sub-compartment and emission scenario implies that the life cycle inventory should accommodate a distinction between air emissions in high and low population-density areas.

\subsection{Future perspectives}

A full quality check of effect data from the two freshwater ecotoxicity data sets is recommended for the second phase of the UNEP-SETAC Life Cycle Initiative, including a check for the occurrence of NOEC extrapolation and for the representation of taxa and trophic levels. Furthermore, research on how to include chronic data and how to estimate average toxicity (based on data for individual single species or averaged on trophic levels) is also needed and strongly recommended for the second phase of the UNEP-SETAC Life Cycle Initiative.

For the upcoming second phase of the UNEP-SETAC Life Cycle Initiative the following future activities are foreseen:

- Increase of substance coverage and quality assurance of substance data;

- User-friendly programming of the model, which currently only exists as a research model in Excel;

- Including parameter uncertainty in the uncertainty estimates on the USEtox CFs;

- Development of USEtox to accommodate the metals;

- Development of USEtox to accommodate indoor emissions in homes and workplaces;

- Recommendations regarding differentiation between midpoint and endpoint characterisation;

- Full documentation of USEtox; 
- Research on how to include chronic data and how to estimate average toxicity (single species or trophic levels)

- Inclusion of terrestrial and marine ecotoxicity as endpoints in USEtox;

- Reliability check of freshwater ecotoxicity CFs based on one or two effect data only (including a check for the occurrence of NOEC extrapolation and on the representation of taxa and trophic levels)

- Industry workshops on comparative assessment of chemicals and training courses in USEtox;

- Consensus building among stakeholders.

\section{Supporting Information}

A set of supporting information is available online, accompanying this paper. It comprises a full list of recommended and interim CFs, including a selection of intermediary parameters: intake fractions (inhalation, ingestion), effect factors (cancer, non-cancer, freshwater ecotoxicity), fate factors (air, water, soil), etc. in Excel format. The complete chemical data base and the model are available through the authors and might become accessible via the internet (under www.usetox.com) in the future. Further, an overview of the general qualitative model-analysis criteria and a brief summary of the qualitative analysis results are included in the supporting information.

\section{Acknowledgement}

Most of the work for this project was carried out on a voluntary basis and financed by in-kind contributions from the authors' home institutions which are therefore gratefully acknowledged.

The work was performed under the auspices of the UNEP-SETAC Life Cycle Initiative which also provided logistic and financial support and facilitated stakeholder consultations. The financial support from ACC (American Chemical Council) and ICMM (International Council on Mining and Metals) is also gratefully acknowledged. T. McKone was supported in part by Interagency Agreement DW-89-93058201-1 with Lawrence Berkeley National Laboratory through the US Department of Energy under Contract Grant No. DE-AC02-05CH11231.

A number of persons have contributed to the process and success of the model comparison and scientific consensus model development. The authors are grateful for the participation of Miriam Diamond, Louise Deschênes, Bill Adams, Andrea Russel, Jeroen Guinée, Pierre-Yves Robidoux, Stefanie Hellweg, Evangelia Demou, Stig Irving Olsen, Cécile Bulle, Sau Soon Chen, Manuel Olivera, Julian Marshall, Bert-Droste Franke, Peter Fantke, Oleg Travnikov, Dick de Zwart, Peter Chapman, Kees van Gestel, and Thomas H. Slone.

\section{References}

Aronson D, Boethling R, Howard P, Stiteler W (2006): Estimating biodegradation half-lives for use in chemical screening. Chemosphere 63(11):1953-1960

Bachmann TM (2006): Hazardous Substances and Human Health: Exposure, Impact and External Cost Assessment at the European Scale. Trace Metals and other Contaminants in the Environment, 8. Elsevier, Amsterdam, 570 pp

Bennett DH, Scheringer M, McKone TE, Hungerbühler K (2001): Predicting long-range transport: A systematic evaluation of two multimedia transport models. Environ Sci Technol 35(6):1181

Cowan CE, Mackay D, Feijtel TCJ, van de Meent D, Di Guardo A, Davies J, Mackay N (Editors), 1994: The Multi-Media Fate Model: A Vital Tool for Predicting the Fate of Chemicals. SETAC. SETAC Press, Denver, CO and Leuven, Belgium

Dreyer LC, Niemann AL, Hauschild MZ (2003): Comparison of three different LCIA methods: EDIP97, CML2001 and eco-indicator 99: Does it matter which one you choose? Int J Life Cycle Assess 8(4):191-200

EC 1999: Externalities of Fuel Cycles - ExternE Project. Vol. 7 - Methodology (2nd edition), European Commission DG XII, Science Research and Development, JOULE, Brussels - Luxembourg

EC 2003: Technical Guidance Document on Risk Assessment in Support of Commission Directive 93/67/EEC on Risk Assessment for new notified substances Commission Regulation (EC) No 1488/94 on Risk Assessment for existing substances Directive 98/8/EC of the European Parliament and of the Council concerning the placing of biocidal products on the market - Part I, Institute for Health and Consumer Protection, European Chemicals Bureau, European Joint Research Centre (JRC) Ispra, Italy

EC 2005: ExternE - Externalities of Energy: Methodology 2005 update, Office for Official Publication of the European Communities, Luxembourg

ECOTOX 2001: ECOTOXicology Database system, http://www.epa.gov/ecotox

Fenner K, Scheringer M, Stroebe M, Macleod M, McKone T, Matthies M, Klasmeier J, Beyer A, Bonnell M, Le Gall AC, Mackay D, Van De Meent D, Pennington D, Scharenberg B, Suzuki N, Wania F (2005): Comparing estimates of persistence and long-range transport potential among multimedia models. Environ Sci Technol 39(7):1932

Goedkoop M, Müller-Wenk R, Hofstetter P, Spriensma R (1998): The Eco-Indicator 99 Explained. Int J Life Cycle Assess $3(6): 352-360$

Gold LS, Slone TH, Bernstein L (1989): Summary of Carcinogenic Potency and Positivity for 492 Rodent Carcinogens in the Carcinogenic Potency Database. Environ Health Perspect 79:259-272

Gold LS, Manley NB, Slone TH, Rohrbach L, Backman-Garfinkel G (2005): Supplement to the Carcinogenic Potency Database (CPDB): Results of Animal Bioassays Published in the General Literature through 1997 and by the National Toxicology Program in 1997-1998. Toxicol Sci 85(2):747-808 
Gold LS, et al 2008: The Carcinogenic Potency Database (CPDB), http://potency.berkeley.edu/chemicalsummary.html

Hauschild M, Wenzel H (1998): Environmental Assessment of Products, Volume 2: Scientific background. Kluwer Academic Publishers, Hingham, MA, USA, 565 pp

Hauschild MZ, Huijbregts MAJ, Jolliet O, MacLeod M, Margni M, Van de Meent D, Rosenbaum RK, McKone TE (2008): Building a model based on scientific consensus for Life Cycle Impact Assessment of Chemicals: the Search for Harmony and Parsimony. Environ Sci Technol 42(19)

Heijungs R, Guinée JB, Huppes G, Lankreijer RM, Udo de Haes HA, Wegner Sleeswijk A, Ansems AMM, Eggels PG, van Duin R, Goede AP 1992: Environmental Life Cycle Assessment of Products, Centre of Environmental Sciences, Leiden, The Netherlands

Hertwich E, Matales SF, Pease WS, McKone TE (2001): Human Toxicity Potentials for Life-Cycle Assessment and Toxics Release Inventory Risk Screening. Environ Toxicol Chem 20(4):928-939

Howard PH, Boethling RS, Jarvis WF, Meylan WM, Michalenko EM (1991): Handbook of Environmental Degradation Rates. Lewis Publishers, Michigan

Howard PH, Meylan WM (Editors), 1997: Handbook of Physical Properties of Organic Chemicals. Lewis Publishers, CRC Press cop., 1585 pp

Huijbregts MAJ, Thissen U, Guinée JB, Jager T, Kalf D, van de Meent D, Ragas AMJ, Wegener Sleeswijk A, Reijnders L (2000): Priority assessment of toxic substances in life cycle assessment. Part I: Calculation of Toxicity potentials for 181 substances with the nested multi-media fate, exposure and effects model USES-LCA. Chemosphere 41(4):541-573

Huijbregts MAJ, Geelen LMJ, Van De Meent D, Hertwich EG, McKone TE (2005a): A comparison between the multimedia fate and exposure models CalTOX and Uniform System for Evaluation of Substances adapted for Life-Cycle Assessment based on the population intake fraction of toxic pollutants. Environ Toxicol Chem 24(2):486-493

Huijbregts MAJ, Rombouts LJA, Ragas AMJ, Van de Meent D (2005b): Human-Toxicological Effect and Damage Factors of Carcinogenic and Noncarcinogenic Chemicals for Life Cycle Impact Assessment. Integr Environ Assess Manage 1(3):181-192

Huijbregts MAJ, Struijs J, Goedkoop M, Heijungs R, Hendriks AJ, Van de Meent D (2005c): Human population intake fractions and environmental fate factors of toxic pollutants in Life Cycle Impact Assessment. Chemosphere 61(10):1495-1504

IUCLID 2000: IUCLID CD-ROM Year 2000 edition. Public data on high volume chemicals

Jolliet O, Brent A, Goedkoop M, Itsubo N, Mueller-Wenk R, Peña C, Schenk R, Stewart M, Weidema B 2003a: The LCIA Framework, SETAC-UNEP, Life Cycle Initialive, Lausanne

Jolliet O, Margni M, Charles R, Humbert S, Payet J, Rebitzer G, Rosenbaum RK (2003b): IMPACT 2002+: A New Life Cycle Impact Assessment Methodology. Int J Life Cycle Assess 8(6):324-330

Jolliet O, Hauschild M (2005): The influence of the intermittent character of rain on fate and long range transport of air organic pollutants. Environ Sci Technol 39(12):4513-4522

Jolliet O, Rosenbaum RK, Chapmann P, McKone T, Margni M, Scheringer M, van Straalen N, Wania F (2006): Establishing a framework for Life Cycle Toxicity Assessment: Findings of the Lausanne review workshop. Int J Life Cycle Assess 11(3):209-212

Kawamoto K, MacLeod M, Mackay D (2001): Evaluation and comparison of multimedia mass balance models of chemical fate: Application of EUSES and ChemCAN to 68 chemicals in Japan. Chemosphere 44(4):599-612

Larsen HF, Hauschild MZ (2007): GM-troph: A low data demand ecotoxicity effect indicator for use in LCIA. Int J Life Cycle Assess 12(2):79-91

Ligthart $\mathrm{T}$ et al. (2004): Declaration of Apeldoorn on LCIA of Non-Ferrous Metals. http://lcinitiative.unep.fr/includes/file.asp?site=lcinit\&file=38D1F49D-6D64-45AE-9F64-578BA414E499

Mackay D, Seth R (1999): The Role of Mass Balance Modelling in Impact Assessment and Pollution Prevention. In: Sikdar SK, Diweakar U (Editors), Tools and Methods for Pollution Prevention. Kluwer Academic Publishers, The Netherlands, pp. 157-179

Mackay D, Shiu WY, Lee SC, Ma KC (2006): Handbook of Physical-Chemical Properties and Environmental Fate for Organic Chemicals. Science, Technology, Engineering, I-IV. CRC Press

MacLeod M, Woodfine DG, Mackay D, McKone TE, Bennett DH, Maddalena R (2001): BETR North America: A regionally segmented multimedia contaminant fate model for North America. Environ Sci Pollut Res 8(3):156-163

Maddalena RL, McKone TE, Layton DW, Hsieh DPH (1995): Comparison of multi-media transport and transformation models: Regional fugacity model vs. CalTOX. Chemosphere 30(5):869-899

Margni M, Pennington DW, Birkved M, Larsen HF, Hauschild M 2002: Test set of organic chemicals for LCIA characterisation method comparison

Margni M 2003: Source to Intake Modeling in Life Cycle Impact Assessment. Ph.D. Thesis, Ecole Polytechnique Fédérale de Lausanne (EPFL), Lausanne, Switzerland, 138 pp

Margni M, Pennington DW, Bennett DH, Jolliet O (2004): Cyclic Exchanges and Level of Coupling Between Environmental Media: Intermedia Feedback in Multimedia Fate Models. Environ Sci Technol 38(20):5450-5457

McKone T, Bennett D, Maddalena R 2001: CalTOX 4.0 Technical Support Document, Vol. 1. LBNL - 47254, Lawrence Berkeley National Laboratory, Berkeley, CA 
McKone TE (1993): The Precision of QSAR Methods for Estimating Intermedia Transfer Factors in Exposure Assessments. SAR QSAR Environ Res 1(1):41-51

McKone TE 2001: Ecological Toxicity Potentials (ETPs) for Substances Released to Air and Surface Waters, Environmental Health Sciences Division, School of Public Health, University of California, Berkeley, CA 94720

McKone TE, Kyle AD, Jolliet O, Olsen SI, Hauschild M (2006): Dose-Response Modeling for Life Cycle Impact Assessment - Findings of the Portland Review Workshop. Int J Life Cycle Assess 11(2):137-140

Meylan WM, Howard PH, Boethling RS, Aronson D, Printup H, Gouchie S (1999): Improved Method for Estimating Bioconcentration/Bioaccumulation factor from Octanol/Water partition coefficient. Environ Toxicol Chem 18(4):664-672

NCMS 2008: SOLV-DB, http://solvdb.ncms.org/index.html

Pant R, Van Hoof G, Schowanek D, Feijtel TCJ, De Koning A, Hauschild M, Olsen SI, Pennington DW, Rosenbaum RK (2004): Comparison between three different LCIA methods for aquatic ecotoxicity and a product environmental risk assessment: Insights from a detergent case study within OMNIITOX. Int J Life Cycle Assess 9(5):295

Payet J 2004: Assessing Toxic Impacts on Aquatic Ecosystems in Life Cycle Assessment (LCA). Ph.D. Thesis, Ecole Polytechnique Fédérale de Lausanne (EPFL), Lausanne, Switzerland, 190 pp

Pennington DW, Margni M, Ammann C, Jolliet O (2005): Multimedia fate and human intake modeling: Spatial versus nonspatial insights for chemical emissions in Western Europe. Environ Sci Technol 39(4):1119

Rosenbaum RK 2006: Multimedia and Food Chain Modelling of Toxics for Comparative Risk and Life Cycle Impact Assessment. Ph.D. Thesis, Ecole Polytechnique Fédérale de Lausanne (EPFL), Lausanne, Switzerland, 192 pp

Rosenbaum RK, Margni M, Jolliet O (2007): A flexible matrix algebra framework for the multimedia multipathway modeling of emission to impacts. Environ Int 33(5):624-634

Scheringer M, Wegmann F, Hungerbühler K (2004): Investigating the mechanics of multimedia box models: How to explain differences between models in terms of mass fluxes? Environ Toxicol Chem 23(10):2433

Sinkkonen S, Paasivirta J (2000): Degradation half-life times of PCDDs, PCDFs and PCBs for environmental fate modeling. Chemosphere 40(9):943-949

SRC 2008: Environmental Fate Data Base (EFDB), http://www.syrres.com/esc/efdb.htm

Stroebe M, Scheringer M, Hungerbühler K, Held H (2004): Inter-comparison of multimedia modeling approaches: Modes of transport, measures of long range transport potential and the spatial remote state. Sci Total Environ 321(1-3):1

Travis C, Arms A (1988): Bioconcentration of organics in beef, milk, and vegetation. Environ Sci Technol 22(3):271-274

USEPA 2007: Estimation Programs Interface EPI Suite, http://www.epa.gov/opptintr/exposure/pubs/episuite.htm

Van Zelm R, Huijbregts MAJ, Harbers JV, Wintersen A, Struijs J, Posthuma L, Van de Meent D (2007): Uncertainty in msPAF-based ecotoxicological effect factors for freshwater ecosystems in life cycle impact assessment. Integr Environ Assess Manage 3(2):203-210

Vermeire T, Pieters M, Rennen M, Bos P 2001: Probabalistic assessment factors for human health risk assessment-A practical guide., National Institute for Health and the Environment., Bilthoven, The Netherlands.

Wania F, MacKay D 2000: A comparison of overall persistence values and atmospheric travel distances calculated by various multi-media fate models, WECC Wania Environmental Chemists Corp., under Chlorine Chemistry Council Contracts No. 9461 and 9462, Toronto, Ontario, Canada

Wania F, Dugani CB (2003): Assessing the long-range transport potential of polybrominated diphenyl ethers: A comparison of four multimedia models. Environ Toxicol Chem 22(6):1252

Wegmann F, Cavin L, MacLeod M, Scheringer M, Hungerbühler K (2008): A software tool for screening chemicals of environmental concern for persistence and long-range transport potential. Environ Model Softw in press http://dx.doi.org/10.1016/j.envsoft.2008.06.014

Wenzel H, Hauschild M, Alting L (1998): Environmental Assessment of Products, Volume 1: Methodology, Tools and Case Studies in Product Development. Kluwer Academic Publishers, Hingham, MA, USA, 560 pp

Received:

Fig. 1: Framework for comparative toxicity assessment

Fig. 2: Compartment setup of the consensus model

Fig. 3: Comparison of characterisation factors for organics calculated by the consensus model against the other models for human health impacts due to a continental emission to rural air. The plot shows the model comparison after harmonisation (Montreal workshop)

Fig. 4: Residual error of the human health characterisation factors from USEtox vs. all other models (IMPACT 2002, CalTOX, USES-LCA, EDIP) before (dark grey) and after (light grey) harmonisation

Fig. 5: Comparison of characterisation factors for organics calculated by the consensus model against the other models for aquatic ecosystem impacts due to an emission to water. The plot shows the model comparison after harmonisation (Montreal workshop)

Fig. 6: Residual error of the freshwater ecotoxicity characterisation factors from USEtox vs. all other models (IMPACT 2002, USES-LCA, EDIP) before (dark grey) and after (light grey) harmonisation

Table 1: Key model elements identified in the comparison and implemented in the consensus mode

Table 2: Model uncertainty estimates for the recommended characterisation factors 
Table 1

\begin{tabular}{|c|c|c|}
\hline Topic & Description & How it has been dealt with in USEtox \\
\hline $\begin{array}{l}\text { Fate: Inclusion of an } \\
\text { urban air } \\
\text { compartment }\end{array}$ & $\begin{array}{l}\text { Nesting an urban air box in the continental air box } \\
\text { allowing to account for higher inhalation impacts in } \\
\text { areas with higher population density }\end{array}$ & $\begin{array}{l}\text { Chemicals coming from the urban air compartment are } \\
\text { transferred to rural air via advection, to rural soil via deposition } \\
\text { and to rural surface water via run-off from the surface considered } \\
\text { as } 100 \% \text { paved, or removed via degradation. }\end{array}$ \\
\hline $\begin{array}{l}\text { Fate: Inclusion of a } \\
\text { global zone }\end{array}$ & $\begin{array}{l}\text { Allows for assessment of global-scale impacts for } \\
\text { substances that are subject to long-range transport }\end{array}$ & Nested model structure includes the global scale. \\
\hline $\begin{array}{l}\text { Fate: Accounting for } \\
\text { intermittent rain } \\
\text { events }\end{array}$ & $\begin{array}{l}\text { Many steady-state fate models overestimate transfer } \\
\text { of chemicals from the atmosphere to the surface by } \\
\text { rain because they assume constant rain conditions. }\end{array}$ & $\begin{array}{l}\text { An algorithm approximating the effect of intermittent rain events } \\
\text { (Jolliet \& Hauschild 2005) has been implemented in the } \\
\text { consensus model. }\end{array}$ \\
\hline $\begin{array}{l}\text { Fate: Distinguishing } \\
\text { soil types }\end{array}$ & $\begin{array}{l}\text { Human exposure via agricultural produce is related } \\
\text { to agriculturally used soil only, which represents just } \\
\text { a fraction of the total soil surface. }\end{array}$ & $\begin{array}{l}\text { Using two soil types, agricultural and natural soil, accounts for the } \\
\text { fraction of agricultural soil relative to the total soil surface and } \\
\text { also allows for specific (e.g. pesticide) emissions occurring on } \\
\text { agricultural soil only. }\end{array}$ \\
\hline $\begin{array}{l}\text { Fate: Soil } \\
\text { compartment setup }\end{array}$ & $\begin{array}{l}\text { Soil usually is a complex medium consisting of } \\
\text { several multi-layered sub-compartments with distinct } \\
\text { fate properties. }\end{array}$ & $\begin{array}{l}\text { In order to keep it reasonably simple and transparent, the soil } \\
\text { compartment is a homogeneous single-layer compartment with a } \\
\text { depth of } 10 \mathrm{~cm} \text {. }\end{array}$ \\
\hline $\begin{array}{l}\text { Fate: Marine } \\
\text { compartments }\end{array}$ & $\begin{array}{l}\text { Persistent pollutants (particularly metals) get } \\
\text { unrealistically high characterisation factors due to } \\
\text { long residence time in the deep sea }\end{array}$ & $\begin{array}{l}\text { Deep sea modelled as a sink, exposure and impacts only } \\
\text { modelled in coastal waters. }\end{array}$ \\
\hline Fate: Sediments & $\begin{array}{l}\text { The consideration of sediment compartments in } \\
\text { fresh and marine water and related processes, e.g. } \\
\text { re-suspension and burial, lead to significant } \\
\text { differences between models for individual } \\
\text { substances. }\end{array}$ & Sediment has been omitted as compartment. \\
\hline $\begin{array}{l}\text { Human exposure: } \\
\text { Plant uptake model }\end{array}$ & $\begin{array}{l}\text { Significant differences in vegetation uptake } \\
\text { algorithms were identified in the multimedia } \\
\text { fate/exposure models under consideration. }\end{array}$ & $\begin{array}{l}\text { The consensus model uses a simplified one-compartment } \\
\text { approach suitable to account for chemical exposure limiting the } \\
\text { root concentration factor (RCF) for high } \mathrm{K}_{\text {ow }}\left(>10^{5}\right) \text { compounds to } \\
200 \text { and distinguishing leaf surfaces from overall above-ground } \\
\text { plant tissues when calculating the plant-air partition coefficient. }\end{array}$ \\
\hline $\begin{array}{l}\text { Human exposure: } \\
\text { Biotransfer into meat } \\
\text { and milk }\end{array}$ & $\begin{array}{l}\text { Current biotransfer models for meat and milk are } \\
\text { very uncertain and provide unrealistic results for } \\
\text { highly hydrophobic chemicals. }\end{array}$ & $\begin{array}{l}\text { Due to the lack of updated methods we followed the } \\
\text { recommendation of the European Commission Technical } \\
\text { Guidance Document, truncating the Travis and Arms (1988) } \\
\text { model at log } K_{\text {ow }}>6.5 \text { and }<3 \text { to a constant value (EC 2003). } \\
\text { Biotransfer for meat are corrected for human meat consumption } \\
\text { (beef, pork, poultry, goat/sheep) and their respective individual } \\
\text { farm animal intake and fat content }\end{array}$ \\
\hline Human toxicity effects & $\begin{array}{l}\text { According to recommendations from external experts } \\
\text { (Jolliet et al. 2006, McKone et al. 2006), effect } \\
\text { indicators for human toxicity based on best estimate } \\
\text { of effect concentrations (ED } \mathrm{ED}_{50} \text { or } \mathrm{ED}_{10} \text {, possibly } \\
\text { extrapolated from NOAEL), rather than reference } \\
\text { dose that embeds safety factors. }\end{array}$ & $\begin{array}{l}\text { According to recommendations human effect factors are } \\
\text { calculated as } 0.5 / E D_{50} \\
\text { Route to route extrapolation has been studied in further details. } \\
\text { Factors for chemicals with uncertain extrapolations are marked as } \\
\text { interim. } \\
\text { Regarding the uncertainty related to severity and the lack of } \\
\text { evidence for significant differences when combining dose- } \\
\text { response slope and severity of disability, equal severity has been } \\
\text { assumed so far for cancer and non-cancer. }\end{array}$ \\
\hline $\begin{array}{l}\text { Aquatic ecotoxicity } \\
\text { effects }\end{array}$ & $\begin{array}{l}\text { For the LCA comparative purpose, the } \\
\text { characterisation factor should be chosen at the } \mathrm{HC}_{50} \\
\text { level (geometric mean of effect concentrations, } \mathrm{EC}_{50} \text { ) } \\
\text { not for the most sensitive species (Jolliet et al. 2006, } \\
\text { Ligthart et al. 2004). }\end{array}$ & $\begin{array}{l}\text { Aquatic ecotoxicological effect factors are then calculated as } \\
\mathrm{EF}_{\text {ecotox }}=0.5 / \mathrm{HC}_{50} \text {. This is especially important when comparing } \\
\text { data poor substances with extensively tested substances such as } \\
\text { metals. Factors for data poor chemicals are marked as interim. }\end{array}$ \\
\hline $\begin{array}{l}\text { Overall } \\
\text { characterization } \\
\text { factors }\end{array}$ & $\begin{array}{l}\text { Present model is mostly designed and valid for non } \\
\text { polar, non ionic organic chemicals. }\end{array}$ & $\begin{array}{l}\text { Factors for metals, amphiphilic and dissociating substances are } \\
\text { marked as interim factors. }\end{array}$ \\
\hline
\end{tabular}

Table 2

\begin{tabular}{l|l}
\hline Characterisation factor & GSD $^{2}$ \\
\hline Human health, emission to rural air & 77 \\
Human health, emission to freshwater & 215 \\
Human health, emission to agricultural soil & 2189 \\
Freshwater ecotoxicity, emission to rural air & 176 \\
Freshwater ecotoxicity, emission to freshwater & 18 \\
Freshwater ecotoxicity, emission to agricultural soil & 103 \\
\hline
\end{tabular}



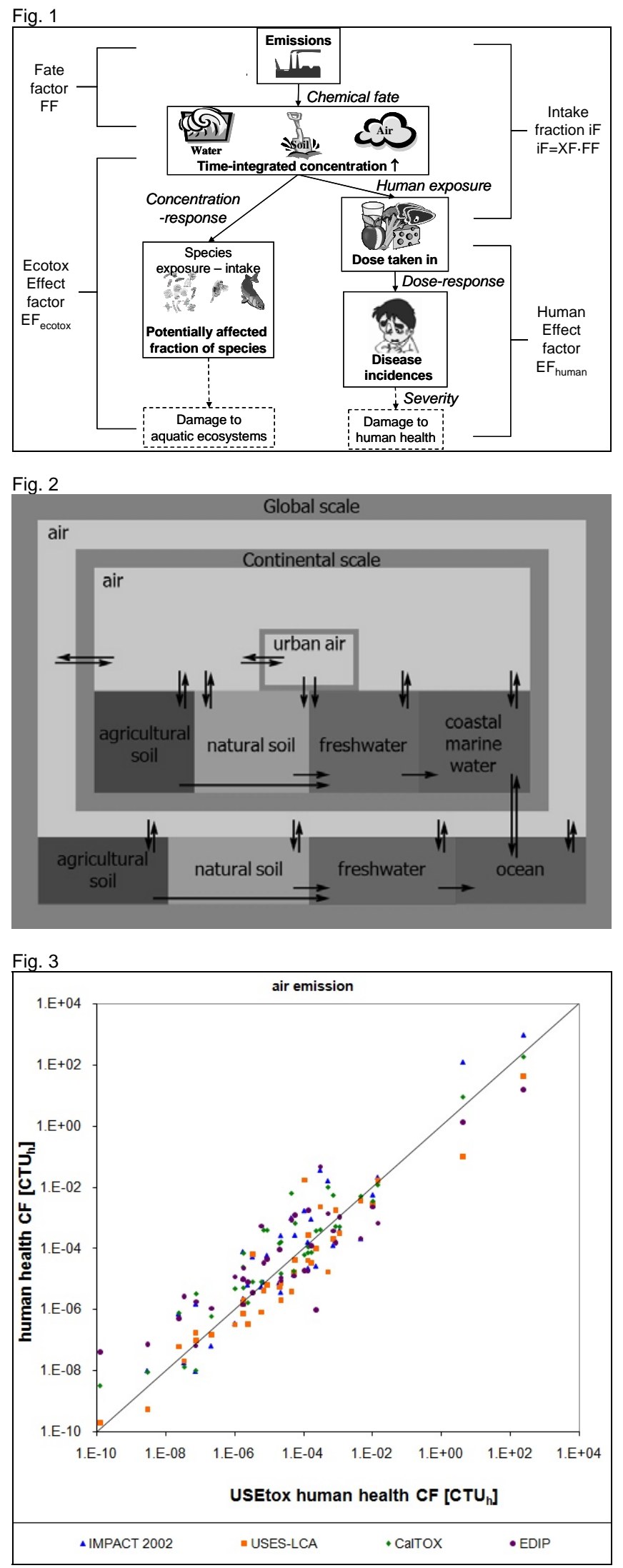

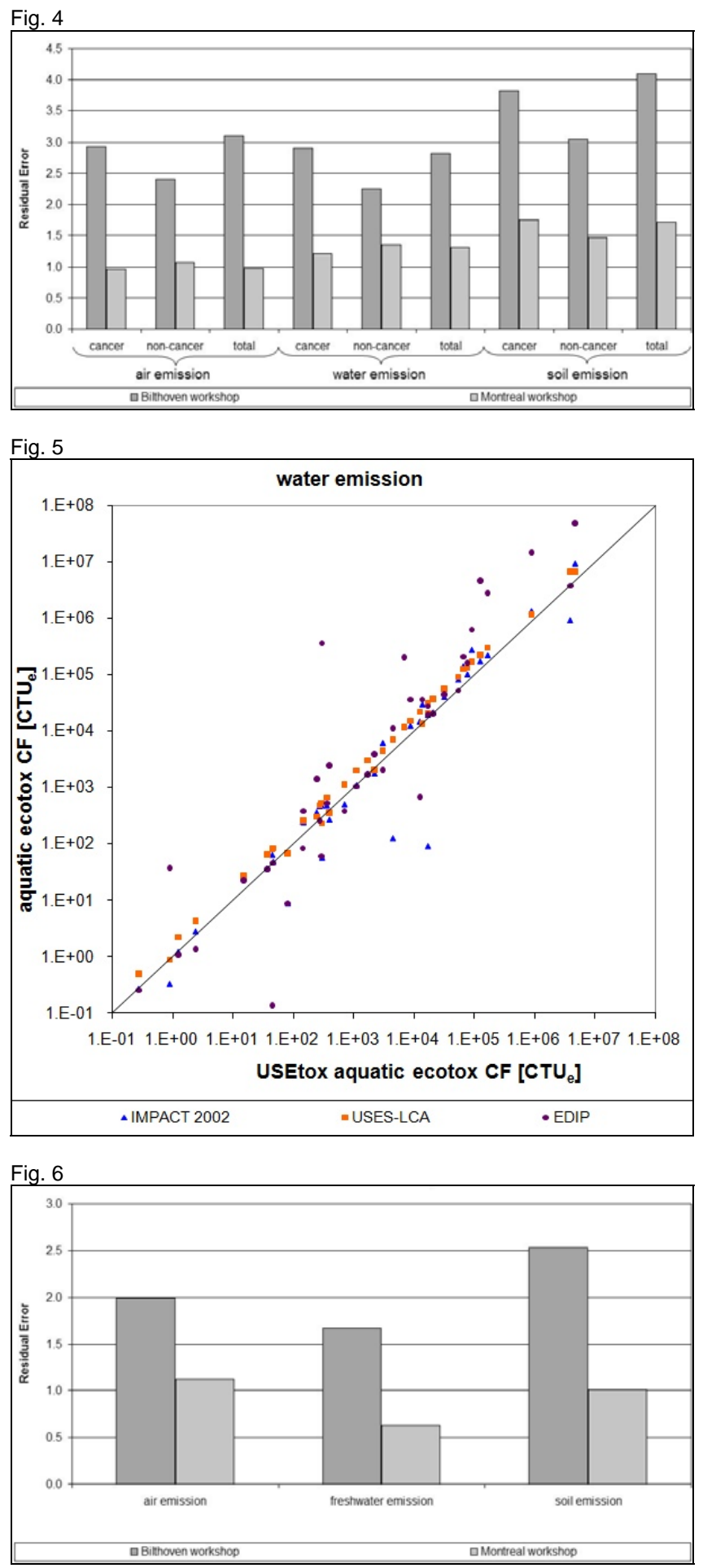